\title{
"Well, good luck with that": reactions to learning of increased genetic risk for Alzheimer disease
}

\author{
Doris T. Zallen, PhD
}

\begin{abstract}
Purpose: Apolipoprotein-E ( $A P O E$ ) genetic testing to estimate risk for developing late-onset Alzheimer disease is increasingly being offered without prior genetic counseling or preparation. Consumer interest continues to grow, raising the question of how best to conduct such testing.
\end{abstract}

Methods: Twenty-six semistructured interviews were carried out to study the reactions of individuals who had already learned of their higher risk after APOE testing had been done because of a family history of Alzheimer disease, or from genetic tests done for other health-related or general-interest reasons.

Results: Adverse psychological reactions were reported by a substantial fraction of the participants, including those who had specifically sought testing, those for whom the information came as

\section{INTRODUCTION}

Among the options provided by genomic medicine are genetic tests that can provide individuals with estimates of their risk for developing specific diseases in the future. Concerns have been raised about the value of one such test: for the e4 allele of the apolipoprotein E (APOE) gene. Presence of the e4 allele increases one's risk for the common, late-onset, form of Alzheimer disease. ${ }^{1-4}$ While $10-15 \%$ of the general population will have developed Alzheimer disease by age 85, for those with one copy of the APOE e4 gene the risk is $25-40 \%$ and for those with two copies the risk is $40-55 \%{ }^{5}$ Major professional organizations have recommended against APOE testing for Alzheimer risk. ${ }^{6-9}$ They are concerned that the test cannot identify those who will definitely develop the disease, because of the involvement of environmental factors and the complex interaction with other genes, and there is the possibility of causing psychological distress since there is no clinical utility in the form of validated medical interventions to ameliorate or prevent the disease. However, even in the absence of such interventions, some consumers find that the test offers personal utility ${ }^{10}$ by enabling them to plan for the future and to participate in Alzheimer prevention trials. ${ }^{11}$

The National Institutes of Health's REVEAL project (Risk Evaluation and Education for Alzheimer's Disease) studied the effect of revealing APOE status to asymptomatic adults with a first-degree relative affected by Alzheimer's. ${ }^{12,13}$ It concluded that the disclosure of APOE status caused only mild and brief psychological problems in those found to have a surprise, those with a family history, and those with no known history. Still, nearly all of those interviewed said that they had benefited in the long term from lifestyle changes, often learned from online sources, that they subsequently made.

Conclusion: The results show that people should be prepared prior to any genetic testing and allowed to opt out of particular tests. If testing is carried out and a higher risk is revealed, they should be actively assisted in deciding how to proceed.

Genet Med advance online publication 8 March 2018

Key Words: APOE; Alzheimer disease; genetic testing; psychological reaction; health-behavior modification

inherited e4 alleles. While reassuring, the REVEAL findings do not reflect the full range of effects associated with obtaining knowledge of one's genetic risk for Alzheimer disease. All of the REVEAL participants received extensive genetic counseling before being allowed into the study, individuals were excluded if they showed signs of depression or anxiety, and only three participants in the study had two copies of the e4 allele and were at highest risk.

In actual practice, APOE testing for Alzheimer risk is arranged through personal physicians or through direct-toconsumer companies. Prior to testing, individuals typically receive no genetic counseling and are given little preparation of any kind. Others unexpectedly learn of their APOE status when having genetic tests for other disease risks, for genealogy, or for general interest. These varied modes of obtaining personal genetic information pose the challenge of determining best practices to guide APOE testing.

This study sought to gain a broader understanding of the effects of APOE testing through an exploration of the reactions of individuals who have actually undergone such testing and discovered that they are at higher risk for Alzheimer disease. Their experiences provide insights that may guide how such testing should proceed in the future.

\section{MATERIALS AND METHODS}

\section{Participants}

The study invited participation from people who had had previous APOE testing and had learned that they were

Department of Science, Technology, and Society, Virginia Tech, Blacksburg, Virginia, USA, and Department of Basic Science Education, Virginia Tech Carilion School of Medicine, Roanoke, Virginia, USA. Correspondence: Doris T. Zallen (dtzallen@vt.edu)

Submitted 19 June 2017; accepted 15 January 2018; advance online publication 8 March 2018. doi:10.1038/gim.2018.13 


\section{ORIGINAL RESEARCH ARTICLE}

heterozygotes or homozygotes for e4. They were reached through ApoE4.Info, an online education and support group (http://www.apoe4.info). This group is a spinoff of a forum originally formed by the direct-to-consumer company 23andMe. The ApoE4.Info board gave permission to recruit volunteers through its website.

\section{Study design}

Semistructured interviews were conducted. The interview guide covered areas such as (i) the reason for seeking testing; (ii) the choice of testing mode; (iii) initial reactions to learning of APOE status and higher risk for Alzheimer disease; (iv) consequences associated with having this information; (v) other factors, including family issues and privacy issues; and (vi) recommendations for how APOE testing should be performed. Each interview was recorded with the interviewee's permission. Interviewees were assured that their personal privacy would be protected. Anonymized interview transcripts were prepared and analyzed by the author using a qualitative-description approach ${ }^{14,15}$ to identify major themes and subsets of those themes. Independent analysis of two transcripts by a second reader yielded almost identical ( $90 \%$ concordance) results. Approval for the study was given by the Virginia Tech institutional review board (15-479), which later approved expansion beyond the original target of 20 interviews in order to achieve thematic saturation.

\section{Participants}

\section{RESULTS}

Table 1 summarizes the main characteristics of the 26 participants. All were college-educated, and several had advanced degrees in science and medicine. They indicated familiarity with searching for and understanding health information from online sources. All had health insurance, although the costs of testing for the direct-to-consumer mode were paid for out of pocket. None opted to follow up with amyloid- $\beta$ PET scans ${ }^{16}$ or tests for other biomarkers to confirm their risk status. The participants had varying degrees of connection to the ApoE4.Info site: some consulted it regularly

Table 1 Characteristics of participants

\begin{tabular}{ll} 
Characteristic & No. of participants \\
\hline Gender: & 20 females; 6 males \\
\hline Age: & $31-78$ years of age (mean: 52) \\
\hline Reason for testing & for Alzheimer risk: 7 \\
\hline & for a different disorder: 12 \\
\hline & for genealogy or general interest: 7 \\
\hline Family history of Alzheimer disease? & yes: 13 \\
\hline Time since testing & no: 13 \\
\hline Genetic status & 8 months-5 years (mean: 2.6 years) \\
\hline & 1 copy of e4: 11 \\
\hline
\end{tabular}

and identified themselves as "members"; some viewed it occasionally, as "guests"; and some labeled themselves "lurkers."

\section{Mode of testing}

The 26 participants all had genetic testing through the directto-consumer company 23andMe (https://www. 23andme.com). Three had first undergone testing through other laboratories chosen by their health-care providers, then followed up with 23andMe. None had received genetic counseling prior to APOE testing.

Before November 2013, the 23andMe genetic results, with interpretations, were sent online directly to the individuals. As part of receiving 23andMe online reports, some sensitive items, including APOE status, were "locked" initially and an alert was given along with a brief informational video. An online checkoff was required before those results could be downloaded. That checkoff was selected by all of the participants. After November 2013, when 23andMe was temporarily enjoined by the US Food and Drug Administration from giving medical interpretations, only raw data were provided. However, individuals could then upload their data onto online sites, such as Promethease (https://promethease. com) and Livewello (https://livewello.com), and obtain interpretations drawn from information collected in SNPedia (https://www.snpedia.com).

Seven individuals were actively seeking to know their APOE status. Those individuals who were not testing specifically for their APOE status had to decide whether to unlock those results in their genetic profiles. The interviews show that, eager to see every aspect of their genetic profiles, most did not take time to reflect on the possible impact of receiving worrisome information. Many did not take the time to look at the video. The decision was usually made quickly, often in a few seconds, in a rush of excitement to obtain the genetic data that was only a click away:

I had never heard of APOE. And so there was, I think, like a little sixty-second video ... about the impact of learning this information. And to be honest with you, I never listened to it. I just click, click, clicked, you know, impatiently trying to get the information.

(Participant A: homozygous, tested for a different health problem)

I was trying to figure out why they were asking this. ... So I really didn't hesitate at all to click on this thing. I was even angry that they asked me ...

(Participant B: heterozygous, general interest)

\section{Immediate reactions to learning test results}

For some, learning of their higher risk was met with relatively mild or brief reactions:

So I clicked on it and I was APOE e4/e4. And ... I kind of expected [it] to some degree ... worst case scenario expectation, so that it couldn't get any worse. It still kind of sucked, but I took it a little more in stride, as in, "Okay, 
what can I do?" ... You know I was almost enthusiastic ... I think in a way it was almost like, "I can use this as a tool to redefine myself."

(Participant C: homozygous, general interest)

I think my first words were, "Oh $s^{\star * * ! " ~} \ldots$ I think my second reaction on the heels of that was, "Really, no surprise." My father had Alzheimer's. ... So, you know there was, sort of that momentary, "Oh, I really didn't want to see this," and then followed by, "But I'm not surprised."

(Participant D: heterozygous, tested for a different health problem)

For others, however, in contrast to the findings of the REVEAL report, reaction to learning of their higher risk was neither mild nor brief. Instead, the test result produced a period of painful, sometimes incapacitating, psychological distress:

There it was! And I didn't even know what it meant. I didn't even know there was that gene ... And then I saw 50\% risk and I'm like " $f^{* * *}, f^{* * *}, f^{* * *} \ldots$.. What do I do? ... It was the most terrifying, unprepared thing ... I was so traumatized for months and months and months ... It was just horrible.

(Participant E: homozygous, tested for a different health problem)

I definitely was emotionally traumatized ... The emotional impact so high, it was strong and huge; it was almost as if I was imagining I was already having issues ... I was going to find a way to have an exit strategy...That's really the only thing that really gave me comfort at that time.

(Participant F: homozygous, tested for a different health problem)

In a few cases, adverse reactions were delayed:

It was more than my brain could handle. It scared me a little bit, but I kind of tabled it. I didn't address it right away. It was in the back of my mind ... Over a period of weeks, I began to get more and more anxious and disturbed ... The more I began exploring [on the Internet], the more terrified I became ... I was devastated ... I considered suicide.

(Participant A)

While quantitative data is not emphasized in qualitative studies such as this, it should be noted that adverse reactions were reported by a substantial fraction of the participants: by those who had specifically sought out APOE testing (3/7) and by those for whom the information came as a surprise (12/19); by those found to be e4 heterozygotes (5/11) and by those found to be e4/e4 homozygotes (10/15); by those with prior personal experience with Alzheimer disease in their families (7/12) and by those with none (8/14); and in all age groups (5/10 for those 50 and below; $7 / 10$ for those $51-59$; and $3 / 6$ for those 60 and above). The only subset that reported no adverse reactions were the 6 male participants in the study.

Part of the distress experienced arose not only from the increased likelihood of a feared disease but from the way that the increased risk was presented. Risk figures were provided either as a percentage (e.g., $50 \%$ by age 85 ) or as a relative risk (e.g., 6 times the average risk). Several had expected to receive only a general indication, something akin to a traffic light: green, yellow, red. Receiving a number, especially one that appeared quite large, intensified their reaction:

The biggest surprise to me was that there was an " $x$ " times greater risk than the average person. That was the stunning part about it. Oh wow, the magnitude of that, it's not what I thought it would be-something like you are a little more likely or not-but not you have 2 copies of the apoe 4 gene and you are at the highest risk of anybody.

(Participant G: homozygous, tested for a different health problem)

All of those interviewed were firm in the knowledge that their genetic signature contained either one or two e4 genes. However, as was found in other studies, ${ }^{17,18}$ recollection of the magnitude of the risk associated with their genotype was variable. Nine individuals (three heterozygotes and six homozygotes) could no longer remember the figure that they were given. Of those who were given a risk percentage, the risk figures recalled by heterozygotes ranged from $12 \%$ to $40 \%$; for homozygotes, from $40 \%$ to $90 \%$. Relative risk numbers recalled by homozygotes ranged up to a frightening "50 times" that of the general population.

It kind of said anywhere from a small number to a big number, from like 6 times to 50 times. I was very confused because if the average person had a $10 \%$ chance of getting Alzheimer's, then if my chance was 50 times that, that would give me over $100 \%$ chance, over $100 \%$ risk. And I really couldn't figure that one out.

(Participant H: homozygous, tested for Alzheimer risk)

Regardless of their initial reasons for genetic testing, most participants expressed unhappiness about the failure of providers to prepare them for information they might receive and for the manner in which it would be presented.

\section{Long-term reactions}

An unexpected, widely shared, finding emerging from the interviews was a significant difference between the short-term and long-term reactions to testing. In the months or years following testing, nearly all (23/26) came to the conclusion that they had benefited in the long term. This includes the individuals experiencing adverse reactions quoted above, who, in retrospect, asserted that they had no regrets:

I have ... changed completely... A year and a half down the line, it has been very positive. I am healthier ... I have sorted out my diet ... and I'm much sharper than I was...

(Participant E)

In the end I'm glad I did it ... And, yes, I'm glad I know because I think I am doing things that I might not do. But, obviously, I wish I didn't have it.

(Participant F) 


\section{ORIGINAL RESEARCH ARTICLE}

I don't regret getting the testing. I think I needed to know this information. I think it makes me more diligent and vigilant than ever about my own health choices and it has caused me to seek out the knowledge and help regarding Alzheimer's that I certainly wouldn't have otherwise.

(Participant I: homozygous, tested for Alzheimer risk)

Their assessments echo the ones offered by those who had not had adverse reactions initially:

Am I upset about it? Yes, sometimes, I get nervous about it. But I know that I am very fortunate. .... There's a lot of things you can do to help yourself and there's a lot of people that are 4/4 who never come down with Alzheimer's. I'm living in a manner that allows me to err in favor of health.

(Participant J: homozygous, tested for Alzheimer risk)

For the last five years, my quality of life has soared because I chose to click on that link. Even if years from now I find something difficult to face, the intervening years have been so much better. I'm sure I'll be challenged at that time but the dividends are in the here and now.

(Participant B)

The benefits described were attributed by participants to the lifestyle changes they made: improved diet; control of cardiovascular and diabetes risk factors; regular exercise; and, for some, the use of supplements. Although they do not know if these changes will prove to be effective in warding off Alzheimer disease, they feel that they are now healthier and mentally more astute than they would have been had they not been tested.

Pathways to identifying and implementing these lifestyle changes differed. Only seven formed action plans in consultation with their doctors. Six others broached the subject with their doctors but were dismissed with responses such as: "Well, good luck with that," "It's very, very sad news," or "It's not a matter of if, it's when." The rest (13/26) chose not to consult their physicians. Most of the interviewees (19/26) proceeded on their own, carrying out intensive online searches for information. Even the more experienced searchers among them said that the task was challenging, confronting them with contradictory data, outdated reports, and wide differences in risk estimates. Still they found that, after a lot of hard work, they were able to identify relevant medical literature. Some were able to make contact with physicians whose work on Alzheimer disease prevention looked promising. The information gathered and discussed on the ApoE4.Info site was also seen as particularly valuable.

The most useful piece for me that mitigated a lot of anxiety was having that community of other apoe4 people. Having the support system was the most important factor that helped me out.

(Participant K: heterozygous, tested for a different health problem)
It is reassuring to hear from people who are not curling up into a ball but are taking action, doing things to mitigate their risk. That was very encouraging.

(Participant L: homozygous, tested for a different health problem)

Several people, in addition to realizing observable health benefits, experienced fundamental changes in mood and outlook. They noted a growing reluctance to take on previously sought-after activities-such as travel or job advancements-fearing that to do so might interfere with their new lifestyle regimen. A few openly wondered whether it would ever be possible to feel happy again.

The interviewees frequently expressed concern that people who have learned of their higher risk for Alzheimer disease but who don't get advice from their physicians on how to proceed or who are not able to seek out health information on their own, are continuing to struggle:

There's a lot to wrap your brain around ... And you don't know how many of them are just feeling completely overwhelmed and helpless because they can't figure it out ...

(Participant M: heterozygous, tested for a different health problem)

For the three individuals who continue to regret learning their APOE status, their major issue is the persistent worry that the knowledge has brought them:

I wish I never knew about this. There's really nothing I can do at my age. It's like a cloud, hanging over my head. I'm basically, I think, optimistic and happy, and I pulled myself out of that really down period. But, it's just a terrible thing hanging over me.

(Participant N: homozygous, tested for general interest)

\section{Sharing genetic information}

Since genes run in families, interviewees were inevitably faced with decisions about whether to share with their close relatives their higher risk for Alzheimer disease. Almost all did share their status, although they were selective. For example, they stated that they chose not to inform relatives who were battling other health issues or those they judged to be psychologically fragile. When the information was shared, it was acted on in different ways: Some relatives followed up with their own direct-to-consumer APOE testing. Test results showing that the 44 allele had been passed on to their children were especially troubling to the parents. Other relatives decided to make health-improving changes without testing and still others chose to have no testing and to make no changes. No instances were reported of family disputes or dysfunction arising from learning of the possibility of higher risk for Alzheimer disease.

Professional societies recommend against genetic testing of children when there is no medical benefit to them, advising, instead, that the children should be allowed to decide for themselves when they reach adulthood. ${ }^{19}$ Most preadult 
children of those in the study have not been tested, although the parents intend to inform them about their potential risk at a future time. However, two of the participants did have their preadult children tested. These parents have not yet informed the children of their higher risk status; they plan to tell them when they reach adulthood.

Despite their willingness to share APOE information within their families, most participants preferred to not disclose their risk status to others beyond the family. Several were unwilling to inform their doctors. Others shared information with their doctors on condition that it be kept out of their health records. A few took steps to have their APOE status removed when it appeared in their records or was used as justification for lab tests. This desire to ensure genetic privacy was driven by concerns that such information could be later used against them by insurance companies and employers. While no one could point to any specific misuse they had experienced, it was a major concern and the main reason given for choosing the direct-to-consumer mode of testing.

\section{DISCUSSION}

Despite the professional communities' recommendations against APOE testing for Alzheimer risk, there is growing interest in such testing within the consumer community. ${ }^{20}$ The recent approval given by the Food and Drug Administration to 23andMe for a battery of tests that include the APOE locus is likely to further spur such interest. ${ }^{21}$ The experiences of those interviewed in this study provide insights into better ways of conducting genetic-risk testing for the lateonset form of Alzheimer disease.

Contrary to the findings reported in the REVEAL study, the present study has found that, as has been noted for other genetic tests, ${ }^{22,23} \mathrm{APOE}$ testing did produce adverse psychological reactions in many participants. A key difference between the two studies is that REVEAL participants had genetic counseling before consenting to testing, while none of the participants in this interview study had the benefit of any prior counseling. Genetic counseling before a genetic-testing decision has long been the standard of care for disorders with features similar to Alzheimer disease as, for example, for Huntington disease, ${ }^{24}$ a late-onset, single-gene disorder with no current means of prevention, and for various forms of cancer where known susceptibility genes increase one's risk. ${ }^{25}$ Practice guidelines issued by the American College of Medical Genetics and the National Society of Genetic Counselors stress the importance of genetic counseling as a means of ensuring informed consent prior to any genetic test decision for Alzheimer disease. ${ }^{26}$

Given the shortage of genetic specialists, including genetic counselors, it will increasingly fall to personal physicians to provide the necessary preparation for patients facing decisions about APOE testing. At present, many physicians report being ill prepared to take on this responsibility. ${ }^{27}$ The fact that participants in this study reported receiving unhelpful and incorrect comments from their physicians supports the argument that better genomics education for physicians is needed. ${ }^{28}$ Also, to supplement physician-patient conversations limited by constraints on office-visit time, new educational tools are needed. Decision aids, in particular, can be very helpful in helping consumers to go beyond general information and to consider the value-laden issues associated with decisions about genetic testing. ${ }^{29}$ One such resource for help with decisions regarding APOE testing is the tool at https://genetestornot.org. ${ }^{30}$

Since direct-to-consumer testing is chosen so often and was used by all the participants in this study, these companies would appear to have a responsibility to provide educational tools prior to testing. As the participants themselves urge, the opportunity to opt out of specific forms of genetic testing is a decision that should be made before any DNA sample is provided, not after the test has been done, with the result only a click away. Another challenge for testing companies is to find ways to protect children from inappropriate testing for adult late-onset disorders when there is no medical benefit to them.

Once genetic-test results are known, simply providing people with the test results is insufficient. Recovery from the adverse psychological reactions that occurred with APOE testing was directly correlated with learning that there are actions to take that might help in reducing risk. ${ }^{31}$ Nearly all the participants in this study did find ways to take such action, albeit sometimes after a long and difficult effort. Their overwhelming recommendation is that, along with receiving test results, people must be actively assisted by the medical and testing communities in determining what reasonable steps they can take.

A limitation of this study is that participants were highly educated and adept at seeking out medical information on their own. Once they found their way to informed physicians, the ApoE4.Info group, and other resources, the interviewees noted that they obtained the information needed to make changes in their health behaviors and come to terms with their APOE status. People less proficient at seeking out medical information were underrepresented in this study. The results reported here may underestimate the potential for prolonged adverse reactions that could occur in the general population. Further studies, using an expanded subject pool recruited in a variety of ways, would be needed to determine the full extent of the consequences of APOE testing. Possible gender differences also warrant further examination.

The insights provided by those interviewed in this study show that people should be educated prior to any genetictesting decision to enable them to decide what information they want-or do not want-to have. In addition, if a test is done, they should be helped to understand the meaning of the results and the possible ways in which they might reduce their risk.

\section{ACKNOWLEDGMENTS}

This study was supported in part by the Department of Science, Technology, and Society at Virginia Tech. 


\section{DISCLOSURE}

The author declares no conflict of interest.

\section{REFERENCES}

1. Corder EH, Saunders AM, Strittmatter WJ et al. Gene dose of apolipoprotein $\mathrm{E}$ type 4 allele and the risk of Alzheimer's disease in late onset families, Science 1993;261: 921-923.

2. Breitner JC, Wyse BW, Anthony JC, et al. APOE-e4 count predicts age when prevalence of $A D$ increases, then declines: the Cache County Study. J Neurol 1999;53:321-331.

3. Christensen KD, Roberts JS, Royal CD, et al. Incorporating ethnicity into genetic assessment for Alzheimer's disease: the REVEAL study experience. Genet Med 2008;10:207-214.

4. Seshadri S \& Wolf PA. Lifetime risk of stroke and dementia: current concepts, and estimates from the Framingham Study. Lancet Neurol 2007;6:1106-1114.

5. Bird TD. Alzheimer disease overview. In: Pagon RA, Adam MP, Ardinger $\mathrm{HH}$, et al. (eds). GeneReviews. University of Washington: Seattle, WA, 23 October 1998. Updated 24 September 2015.

6. American College of Medical Genetics, American Society of Human Genetics Working Group on ApoE and Alzheimer Disease. Statement on the use of Apolipoprotein $E$ testing for Alzheimer disease. JAMA 1995;274:1627-1629.

7. Medical and Scientific Advisory Committee and Alzheimer's Disease International. Consensus statement on genetic testing for Alzheimer disease. Alzheimer Dis Assoc Disord 1995;9:182-87.

8. National Institute on Aging and Alzheimer's Association Working Group. Apolipoprotein E genotyping in Alzheimer disease. Lancet 1996; 347: 1091-1095.

9. Choosing Wisely. ACMG Provides Recommendations on Genetic Testing Through the Choosing Wisely ${ }^{\circledR}$ Campaign. http://mww.choosingwisely.org/ acmg-provides-recommendations-on-genetic-testing-through-the-choosingwisely-campaign/. 10 July 2015. Accessed 12 January 2018.

10. Grosse SD, McBride CM, Evans JP, et al. Personal utility and genomic information: look before you leap. Genet Med 2009;11:575-576.

11. Zallen DT. To Test or Not to Test: A Consumer's Guide to Genetic Screening and Risk. Rutgers University Press: New Brunswick, NJ, 2008:73-107.

12. Green RC, Roberts JS, Cupples LA, et al. Disclosure of APOE genotype for risk of Alzheimer's disease. N Engl J Med 2009;361:245-254.

13. Roberts JS, Christensen KD \& Green RC. Using Alzheimer's disease as a model for genetic risk disclosure: implications for personal genomics. Clin Genet 2011;80:407-414.

14. Hyejin K, Sefcik JS \& Bradway C. Characteristics of qualitative descriptive studies: a systemic review. Res Nurs Health 2017:40:23-42.

15. Neergaard MA, Olesen F, Andersen RS \& Sondergaard J. Qualitative description-the poor cousin of health research? BMC Med Res Methodol 2009;9:52.
16. Huynh RA \& Mohan C, Alzheimer's disease: biomarkers in the genome, blood, and cerebrospinal fluid. Front Neurol 2017;8:102-116.

17. Eckert SL, Katzen H, Roberts JS et al. Recall of disclosed apolipoprotein $E$ genotype and lifetime risk estimate for Alzheimer's disease: the REVEAL study. Genet Med 2006;8:746-751.

18. Lock M, Freeman J, Chilibeck G, et al. Susceptibility genes and the question of embodied identity. Med Anthropol Q 2007;21:256-276.

19. National Society of Genetic Counselors, Genetic testing of minors for adult-onset conditions. 15 February 2017. https://www.nsgc.org/p/bl/et/ blogaid $=860$. Accessed 12 January 2018 .

20. Re/code Decode hosted by Kara Swisher. Interview with Anne Wojcicki released 3 April 2016. https://itunes.apple.com/us/podcast/recode-decode-hosted-by-kara/id1011668648?mt = 2\#episodeGuid = gid $\%$ 3A\%2F\%2Fart19-episode-locator\%2FV0\%2FXjMqFQjIEjXmQTYNq 1 kLNI8CPNiyo-to7ChjXCLSdA Accessed 12 January 2018.

21. US Food and Drug Administration. FDA allows marketing of first direct-to-consumer tests that provide genetic risk information for certain conditions. 6 April 6 2017. https://www.fda.gov/NewsEvents/ Newsroom/PressAnnouncements/ucm551185.htm Accessed 12 January 2018.

22. Quaid KA \& Morris M. Reluctance to undergo predictive testing: the case of Huntington disease. Am J Med Genet 1995;45:41-45.

23. Zallen DT. Does it Run in the Family? A Consumer's Guide to DNA Testing for Genetic Disorders. Rutgers University Press: New Brunswick, NJ, 2008.

24. Huntington's Disease Society of America. Genetic testing protocol for Huntington's disease. 2016. http://hdsa.org/wp-content/uploads/ 2015/02/HDSA-Gen-Testing-Protocol-for-HD.pdf. Accessed 12 January 2018.

25. American Society of Clinical Oncology, Policy statement update: genetic testing for cancer susceptibility J. Clin Oncol. 2003;21:2397-406.

26. Goldman JS, Hahn SE, Williamson Catania J, et al. Genetic counseling and testing for Alzheimer disease: joint practice guidelines of the American College of Medical Genetics and the National Society of Genetic Counselors. Genet Med 2011;13:597-605.

27. Klitzman R, Chung W, Marder $K$, et al. Attitudes and practices among internists concerning genetic testing. J Genet Counsel 2013;22:90-100.

28. Feero WG \& Green ED. Genomics education for health care professionals in the 21st century. JAMA 2011;306:989-990.

29. Stacey D, Légaré $F$, Lewis $K$, et al. Decision aids for people facing health treatment or screening decisions. Cochrane Database Syst Rev 2017; Issue 4. Art. no.: CD001431. doi:10.1002/14651858.CD001431.pub5.

30. Ekstract M, Holtzman, GI, Kim KY, et al. Evaluation of a Web-based decision aid for people considering the APOE genetic test for Alzheimer risk. Genet Med 2017;19:676-682.

31. Baumgart M, Snyder, HM, Carrillo MC, et al. Summary of the evidence on modifiable risk factors for cognitive decline and dementia: a population n-based perspective. Alzheimers Dement 2015;11:718-726. 